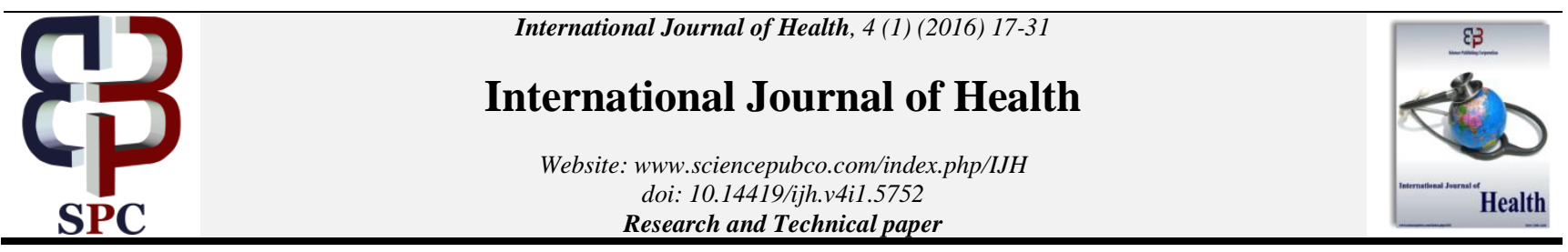

\title{
Conceptual framework for the formulation of strategies to support registered nurses in their utilisation of the nursing process when executing their roles and functions in local-level Primary health care (PHC) practicein Namibia
}

\author{
Hermine Iita $^{1}{ }^{*}$, Scholastika Iipinge ${ }^{2}$, Agnes Van Dyk ${ }^{3}$ \\ ${ }^{1}$ Lecturer School of Public Health, University of Namibia, Oshakati Campus \\ ${ }^{2}$ Professor and Dean of Nursing School, Welwitchia University, Windhoek: Namibia \\ ${ }^{3}$ Professor and Director of Nursing School. International University of Management, Windhoek: Namibia \\ *Corresponding authorE-mail: hiita@ unam.na
}

\begin{abstract}
This paper describes the conceptual framework upon which the development of strategies to support use of the nursing process by registered nurses in local-level Primary health care practice in Namibia was based. The conceptual framework was developed based on the findings of phase 1 of this study, which was a situational analysis to explore and describe the use of the Nursing Process by registered nurses in local level primary health care practice in Namibia and to identify constraints that registered nurses in local level Primary health care practice face as they implement the nursing process in their daily practice. The study was conducted in four phases namely as follow: Phase1: Needs assessment quantitative survey; Phase 2: Conceptualisation of findings from phase 1; Phase 3: Development of strategies to support the roles and functions of the registered nurse in local level PHC and Phase 4: Validation of these strategies. This article focusses on Phase 2: Conceptualisation of findings from phase 1 and it describes objectives 4 of the study namely, to develop a conceptual framework on which to base the formulation of relevant strategies.

From phase 1 which focused on needs assessment, findings indicate that registered nurses in local level Primary health care practice in Namibia fulfill most of their expected role functions. However, five main problem areas were identified. The challenges identified were categorised according to the five elements of PHC and management, namely, water and sanitation and related environmental health issues; nutrition and food supply; health education and communication; community diagnosis and care; and management support or administration, including research.

It was concluded that strategies needed to be developed to support registered nurses in their daily local Primary health care practice.

The development of the conceptual framework, which guided the development of strategies to support registered nurses use the nursing process in local level Primary health care practice, makes this study an original contribution to the body on knowledge.
\end{abstract}

Keywords: Conceptual Framework; Local-Level Primary Health Care; Nursing Process; Primary Health Care; Registered Nurse; Strategies; Support.

\section{Introduction}

This article is extracted from the authors study "Strategies to support utilization of the nursing process by registered nurses in local level Primary health care practice in Namibia. "The purpose of this study was to explore and describe the use of the nursing process by registered nurses in local level primary health care practice in Namibia. The findings were used to serve as a basis to develop strategies to support registered nurses in their daily local PHC practice. Before the strategies were developed in this regard, a conceptual framework was developed on which the development of strategies was based.

Namibia is a country that has after its idependence in 1990 adopted Primary health care as an approach to render health care services to its people and has tried to re-orient health care services provision to meet the demands of this approach. This reorientation included the training of health care workers including nurses Government of the Republic of Namibia, Ministry of Health and Social Services (GRNMOHSS, 1992).

Primary health care (PHC) refers to essential health care and is based on practical, scientifically sound and socially acceptable methods and technology which are made universally accessible to individuals and families in the community and at a cost that the community and the country are able to afford and maintain at every stage of their development in the spirit of self-reliance and self-determination. (Monekoso 1994; WHO 2009).

Registered nurse should use the nursing process to render PHC. The nursing process is a systematic method of assessing data, coming to a conclusion (diagnosis), planning the activities of care accordingly, implementing these activities of care, evaluating the progress and recording everything that has been done (Jooste, 2010; Searle, Human \& Mogotlane, 2009).

From phase 1 which focused on needs assessment, findings indicate that registered nurses in local level Primary health care practice in Namibia fulfill most of their expected role functions. How- 
ever, five main problem areas were identified. The challenges identified were categorised according to the five elements of PHC and management, namely, water and sanitation and related environmental health issues; nutrition and food supply; health education and communication; community diagnosis and care; and management support or administration, including research.

It was concluded that strategies needed to be developed to support registered nurses in their daily local Primary health care practice.

The development of the conceptual framework, which guided the development of strategies to support registered nurses use the nursing process in local level Primary health care practice, makes this study an original contribution to the body on knowledge.

\section{Purpose of the conceptual framework on which to base the development of strategies to support utilisation of the nursing process by registered nurses in local- level primary health care practice in Namibia}

The purpose of this paper is to conceptualise the empirical findings which arose from phase 1 in this study and which reflected the execution of the role and function of the registered nurses using the nursing process in local-level PHC practice in Namibia The ultimate aim of the study is to develop strategies to support registered nurses in their execution of their role and functions regarding daily $\mathrm{PHC}$ practices.

A conceptual framework organises a visual representation of the events taking place in a certain situation in such a way that they are made clear to the readers. It is possible, from what is presented in a framework, to obtain a clear idea of the situation as well as the actions that may be taken to ensure that matters work in the best way possible (Babbie, 2008). Based on the study findings and the literature review, the researchers in this study identified certain areas that required improvement in respect of the fulfilment of the roles and functions of registered nurses in local health facilities in the health districts in Namibia. Based on the above background, a conceptual framework for the study was developed, which served as a basis on which the strategies formulated to support the registered nurses in utilising the nursing process in their daily PHC practice in Namibia is being based on this framework.

Questionnaires were used to gather the relevant information and the five main areas in terms of which registered nurses need support in executing their roles and functions were revealed. These areas included water and sanitation and other environmental health issues; health education and communication, including outreach activities; nutrition and food supply; community diagnosis and care as well as management support or administrative functions in PHC, including research and the education of health workers, and fellow registered nurses. These main areas were arrived at by classifying the concepts that related both to the elements of PHC and the management of such services with the classification of the concepts being the result of a logical reasoning process on the part of the researcher. The reader is referred to a different paper titled "The level at which registered nurses utilize the nursing process in local-level Primary health care practice in Namibia" if need be

\section{The conceptual framework for developing strategies to support utilisation of the nurs- ing process by registered nurses in local- level primary health care practice in $\mathrm{Na}$ - mibia}

The conceptual framework for the development of strategies in this study is structured according to the survey list suggested by Dickoff, James, \& Wiedenbach (1968). This survey list facilitates the identification and categorisation of major concepts for further refinement, thus ensuring the logical development of the practice strategies. In addition, Dickoff et al.'s (1968) list includes the following components: the agent, context, recipient, dynamics, procedure of the activity and terminus. These components are presented in figure 1

Agent: The agent is the researcher, who, in this study is both an educator and a registered nurse. Thus, in the context of this study, the researcher, as agent, in consultation with the Director for Primary Health Care in the MOHSS, had to provide the activity, namely, the strategies to support registered nurses in fulfilling their roles and functions in PHC.

Recipient: The recipient is the person whom, in the context of this study, the strategies will benefit - the registered nurses and their supervisors, who were also registered nurses, but serving in supervisory positions in order to ensure that the roles and functions of the registered nurses in PHC were being satisfactorily fulfilled.

Procedure: In the context of this study the procedure refers to the facilitation of the development of strategies to be used by registered nurses and supervisors in their utilisation of the nursing process as regards the implementation of the PHC elements.

Context: For the purpose of this study, the context refers to the environment of the health facilities in health districts in which PHC is being delivered outside of hospitals.

Dynamics: In the context of this study the dynamics refer to the challenges being faced by registered nurses in their daily fulfilment of their roles and functions. The dynamics indicated by the registered nurses and their supervisors who participated in this study include the following:

- Registered nurses in local-level PHC facilities do not adequately assess issues regarding environmental health, for example, the safety of drinking water.

- Not enough discussion with patients/clients on issues regarding environmental health.

- At times little or no contact with community health workers.

- Assessment of waste disposal not carried out by a number of registered nurses.

- Other environmental health hazards, including unhygienic conditions and noise, also inadequately assessed.

- Inadequate assessment of housing conditions of clients in the catchment area.

- Registered nurses do not carry out sufficient education of both patients and fellow health workers.

- Inadequate assessment of the developmental status of school children.

- Poor assessment of social problems of families and communities in the catchment area.

- Inadequate assessment of need for home care.

- Insufficient planning for outreach services of all types.

- Inadequate provision of home care.

- Lack of participation by registered nurses in health service management functions, including planning of PHC delivery, budgets and writing proposals

Some nurses were unaware of the existence of such functions while others felt that these were the responsibilities of supervisors.

- Inadequate staffing is one of the main reasons why the implementation of most of the functions pertaining to $\mathrm{PHC}$ is inadequate.

- Registered nurses do not carry out sufficient research.

Thus, if the roles and functions of registered nurses as regards the provision of PHC services are to be sufficiently fulfilled in their daily practice, it is essential that strategies and action plans be developed and implemented, with these strategies and action plans being based on overcoming the challenges that have been identified and which are listed above.

Terminus: In the context of this study the terminus refers to the outcomes that will result from the implementation of solutions to the challenges encountered in the daily practice of registered nurses in local-level PHC facilities.

These components will be discussed in more detail below but, first, figure 1 presents a diagrammatic presentation of the components. 


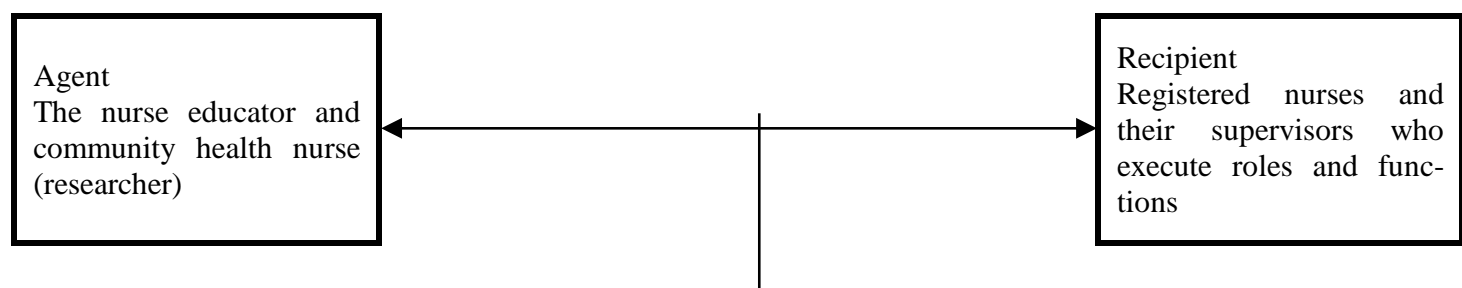

Procedure

Facilitating strategies to support registered nurses in executing roles and functions in PHC practice

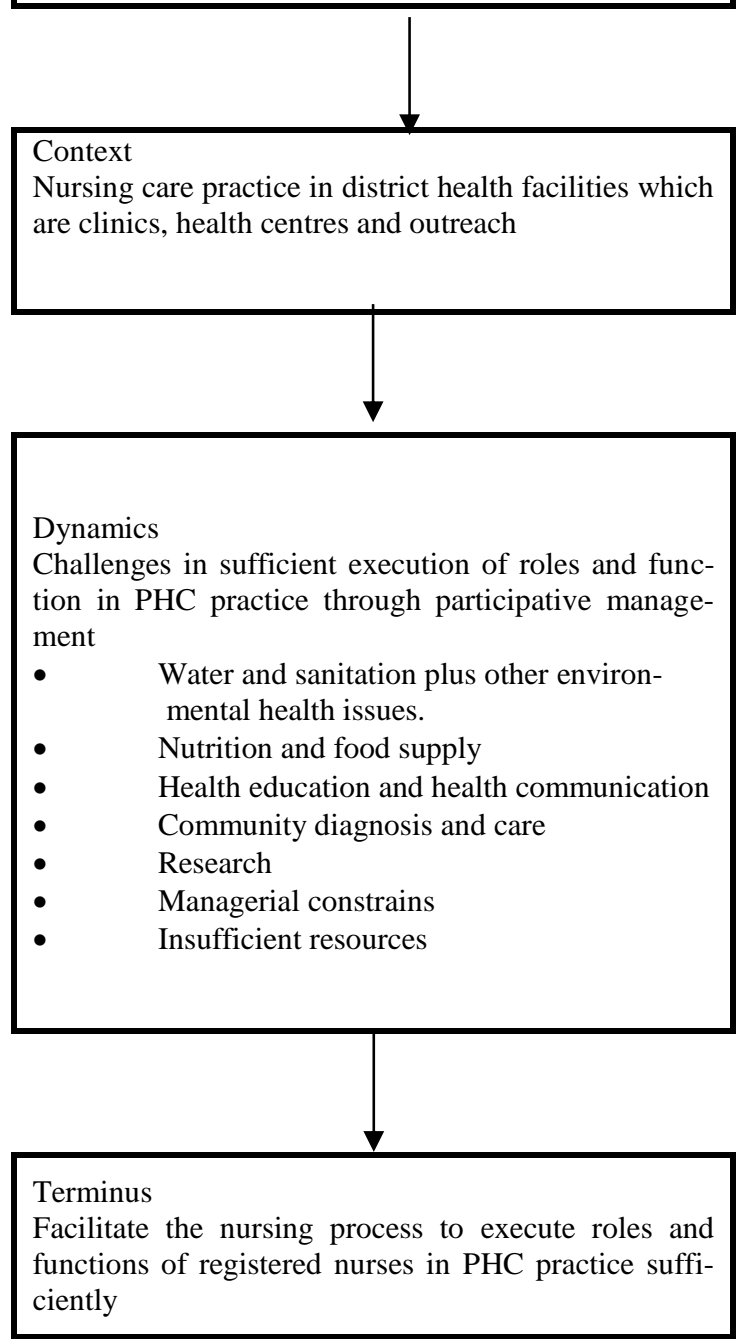

Fig. 1: The Reasoning Map.

\subsection{Agent: researcher}

For the purpose of this study the principal researcher, who are both an educator and a registered nurse, is the agent and, thus, she is the one who provides the activity, namely, the strategies to support registered nurses in utilising the nursing process to implement the elements of PHC in their daily facility practice.

In order for the agent to facilitate the development of such strategies, it requires, firstly, that the researcher, as the agent, possess the personal qualities needed to build good interpersonal relationships with the recipients, namely, the registered nurses and their supervisors. Secondly, as an advanced community nurse practitioner, the researcher should have a clearly identifiable clinical role in guiding and supporting the registered nurses in local-leve PHC practice. It emerged from the study results that the registered nurses needed guidance and support with regard to utilising the nursing process in their daily PHC practice. This was evident in the views they expressed concerning their inadequate execution of certain of the elements of PHC.

An agent is an individual who creates awareness amongst service providers of the acceptable quality of the services offered through governance, integrity and dignity and effective cooperation among team members. Mathis and Jackson (2000) are of the opinion that an agent is a person whose presence has a positive effect on something that is being implemented, for example strategies. This statement correlates with the fact that, in this study, the researcher is the agent who will develop the strategies (procedure) to support registered nurses and their supervisors in the fulfilment of their roles and functions with regard to local-level PHC.

Figure 2 illustrates the various roles assumed by the agent when facilitating the development of such strategies. 


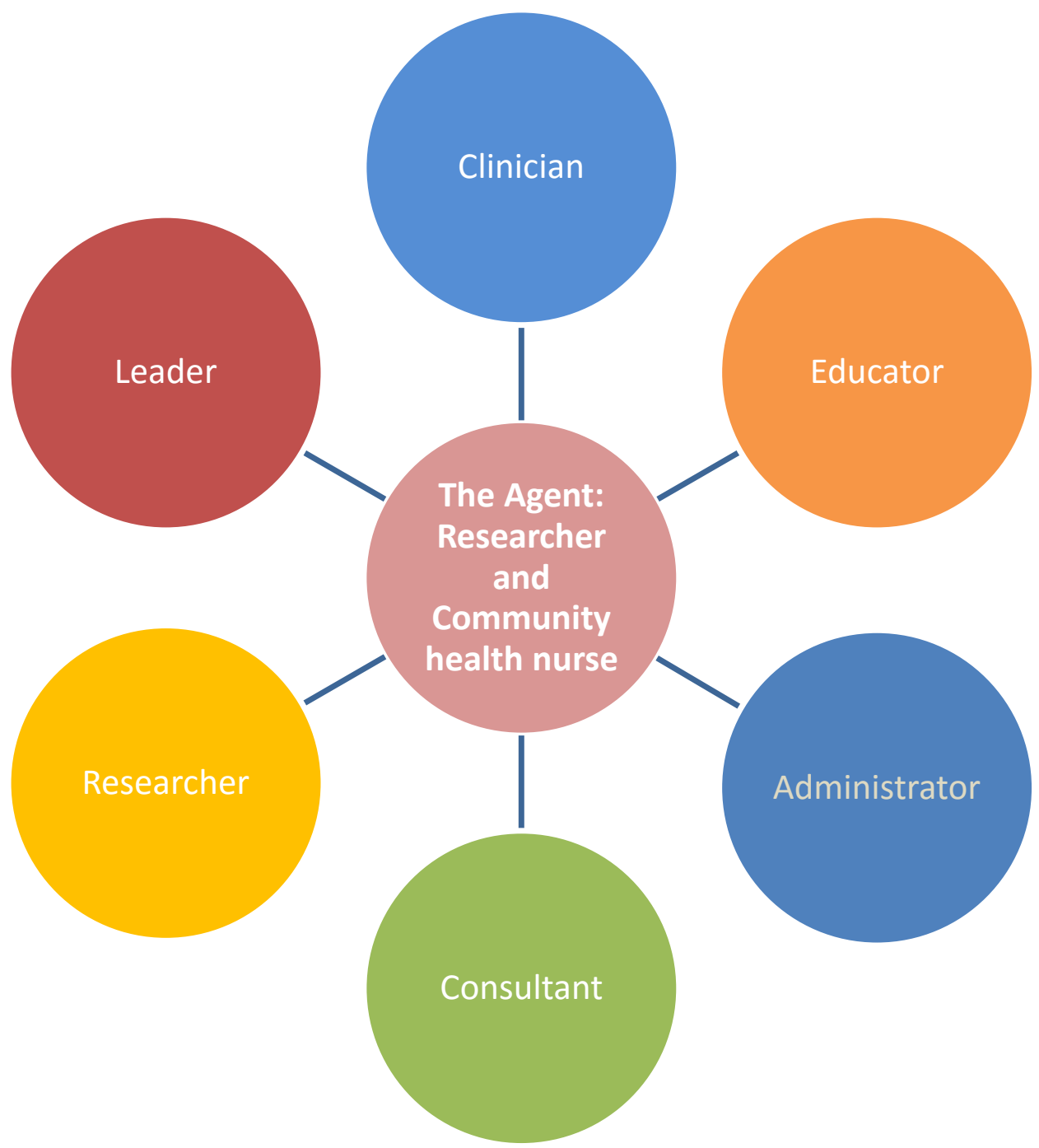

Fig. 2: The Agent.

The agent, in facilitating the development of strategies, is enabled by her capacity to serve as leader, educator and consultant (Stanhope \& Lancaster, 2006) in empowering registered nurses to fulfil their roles and functions. In addition to these three roles, the agent also fulfils the three roles of clinician, administrator and researcher. All these roles together enabled the agent to contribute to the empowerment of registered nurses in local-level PHC.

Six roles enabled the agent to facilitate the development of the required strategies. In figure 2 the four roles of leader, researcher, consultant and educator are highlighted, indicating the active role of the researcher in developing strategies during the research study, while the roles of clinician and administrator are not coloured and these indicate that the researcher recognised that she was not in charge of the PHC practice or administration/management thereof, but that she is a mere nurse professional, who was able to serve as a resource person to the registered nurses and their supervisors. The agent was aware that the final decision to accept or reject the strategies developed lay with the registered nurses and their supervisors, as well as the managers in PHC.

The six roles of the agent are discussed below:

Leader: As a leader, the agent served to facilitate the adoption of a culture that would reinforce the slogan that effective nursing leaders understand the concept of service leadership. This, in turn, involves encouraging the implementation of all steps taken to ensure that the customers (clients) come first, even if this may bring about some changes/adjustments in the organisational bureaucracy (Amos, Ristow, Ristow, \& Pearse, 2008; Jooste, 2009; Stanhope \& Lancaster, 2006; Tomey, 2009;)
Educator: In the context of the study, the agent, as educator, advises on the facilitation of identifying at risk groups within a community, the implementation of health education and the promotion of a healthy lifestyle for individuals, families, aggregate groups and the community, as well as for health care workers (Stanhope \& Lancaster, 2006; Tomey, 2009; Geyer, Mogotlane \& Young, 2009; Smit, Cronje, Brevis \& Urba, 2007).

Consultant: As a result of her knowledge and experience in clinical nursing, education, research and administration, the agent, as consultant, is able to serve as a guide to both the registered nurses in PHC facilities and to their supervisors on issues regarding the assessment of individuals, families, groups and communities in order to identify problems and propose possible innovations to client services (Stanhope \& Lancaster, 2006; Amos et al., 2008; Jooste, 2009).

Clinician: In her capacity as clinician the agent has a responsibility to advise and offer suggestions on best practices regarding the overall assessment, planning, development, coordination and evaluation of innovative programmes to meet the community health needs identified (Stanhope \& Lancaster, 2006; Mank, 2006; Gopee, 2008).

Administrator: In her capacity as administrator the agent may suggest actions on administrative matters within the PHC context, including suggestions on issues related to decision making and problem solving, advising on the management of personnel as well as health programmes that include budgeting, establishing quality control mechanisms and programme planning and influencing the policies, public relations and marketing of PHC services (Stanhope \& Lancaster, 2006; Tomey, 2009). 
Researcher: In her capacity as researcher, she identifies, defines and investigates clinical nursing problems and report findings. She also encourages peer relationships with other professions and contributes to health care policy and decision making. In addition, she carries out relevant research studies that will contribute to improved nursing practice in local-level PHC (Stanhope \& Lancaster, 2006). Jamerson and Vermeersch (2012) identify the following three main roles of the research facilitator, namely, conducting research; developing research capacity and building a research culture within the organisation.

One of the essential personal qualities of the agent in terms of implementing the strategies developed is the ability to build good interpersonal relationships with all concerned in managing PHC. Thus, in terms of her relationship with others, the agent should be able to

- Establish and maintain positive relationships based on mutual trust

- Work collaboratively

- Display a supportive facilitation by showing concern and interest

- Communicate effectively

- Be sensitive to the needs of registered nurses

- Be transparent (Stanhope \& Lancaster 2000; Tomey, 2009; Ginger \& Davidhizar, 2008)

The agent, who in this study is also the researcher and a lecturer, should have both advanced knowledge of PHC services and the nursing process, as well as the skills required to act as a leader. Advanced nursing practice is characterised by a depth and breadth of knowledge in a specific field, in this case, nursing and PHC, as well as the ability to incorporate this knowledge into teaching, theory and practice, leading and consultancy. In other words, the advanced nurse practitioner guides the practice of nursing (Stanhope \& Lancaster 2000). Accordingly, the strategies developed must be of such a quality that they will support and motivate the registered nurses to make a difference in local-level $\mathrm{PHC}$ practice. In addition, it is essential that the agent possess certain characteristics that will empower and support the strategy development process in terms of registered nurses' use of the nursing process. These characteristics will be discussed in the following sections: Competency

According to Tomey (2009), Amos et al. (2008), Geyer et al (2009), Berman et al. (2008) and Smit et al. (2007), it is essential that, in the context of this study, the agent have expert knowledge and skills as regards her role of guiding and supporting the registered nurse in fulfilling her roles and functions in PHC practice. Leadership
Nurse Managers need effective leadership, interpersonal, organisational and political skills. With today's strong emphasis on teamwork, partnership and coalition, management skills are focusing increasingly on coaching and leading empowered groups. Thus, the leadership essential to these roles involves identifying a vision and influencing others to realise the vision, while considering the wellbeing of clients, flexibility and the ability to interact comfortably with different types of people and cultures (Hess \& Cameron, 2006; Daft, 2010; Tomey, 2009; Amos et al., 2008; Geyer etal., 2009; Gopee, 2008; Jooste, 2009; Smit et al.,2007).

Critical thinking

Critical thinking involves values and also renders assumptions explicit and encourages creativity and innovation (Ivancevich, Konopaske, \& Matteson, 2008; Tomey, 2009; Pretorius, 2008; Jooste, 2009; Berman et al., 2008; Smit et al., 2007). In terms of facilitating the strategies developed in the context of this study, critical thinking is required because it encourages reflection on the connections between the sociocultural and biophysiological aspects of both health status and health care services.

\subsubsection{Concluding statement for the agent}

In conclusion, the agent - the researcher in the context of this study - is the person who developed the strategies designed to support registered nurses in their roles and functions in local-level PHC practice. This, in turn, required that the agent (researcher) established a special relationship with the recipients and, furthermore, it required characteristics such as competency, leadership, perseverance and trust.

\subsection{Recipient (registered nurses)}

According to Dickoff et al. (1968), the recipient is defined as the person who receives. Thus, in this study, the recipient refers to those persons who will benefit from the strategies, namely, the registered nurses who practise in local-level PHC facilities and their supervisors who are also registered nurses but who are serving in supervisory positions in order to ensure that the roles and functions of the registered nurses in PHC are being satisfactorily fulfilled.

In figure 3 the recipient represents the core components of nursing care, namely, professional roles and functions, professional values and professional characteristics. According to this figure, both the registered nurses and the supervisors of PHC are the rightful owners of PHC practice.

The discussion of the recipient will, thus, be based on the core components of nursing care as depicted in figure 3 below:

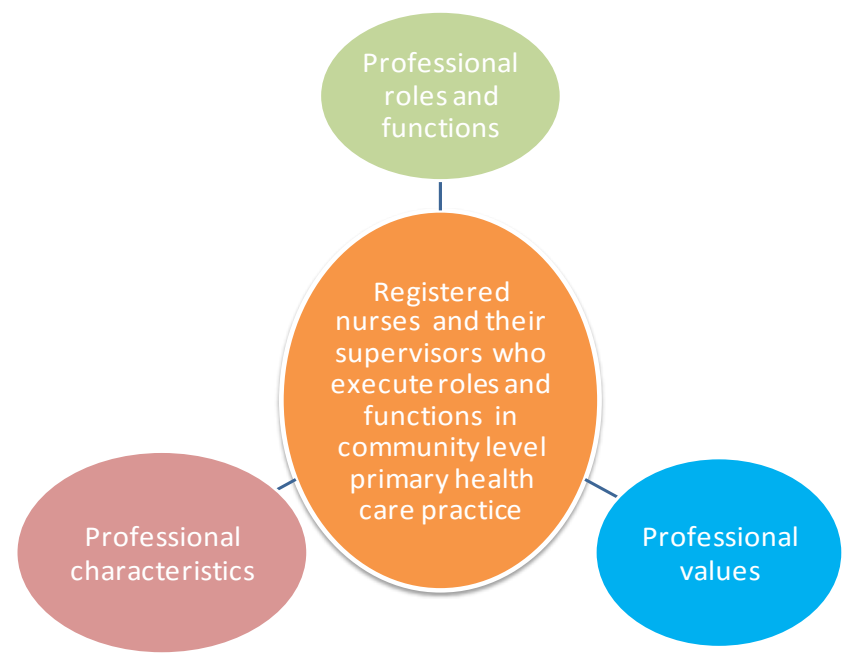

Fig. 3: The Core Components that Guide the Nursing Care Provided by the Recipient. 


\subsubsection{The roles and functions of the recipients}

It is clear from the study results that registered nurses do not always fulfil their roles and functions in PHC delivery. Thus, if the registered nurses are to be the beneficiaries of the strategies designed to support them, it is essential that they revisit these roles and functions as professional nurses, both in terms of the characteristics that are required of them to fulfil these functions and the professional values they will need.

As mentioned earlier, in this study, the registered nurses in locallevel health facilities where PHC is provided were the recipients of the activity, namely, the strategies aimed at supporting their execution of their roles and function in fulfilling the PHC elements using the nursing process as a framework. The registered nurses in this case may also be the supervisors. It became clear from the study results that the registered nurses were encountering certain obstacles in their execution of their roles and functions in the provision of local-level PHC. These obstacles included the following:

- Inadequate assessment by registered nurses of water and sanitation and other environmental health promotion.

- Insufficient assessment of food hygiene.

- Insufficient participation by registered nurses in activities related to the health education and health communication (motivation and education) in the community, including outreach services.

- Inadequate assessment of the social problems of families and the community as a component of community diagnosis and care.

- Inadequate involvement in functions related to management or administration, including financial planning and management, and a lack of skills as regards conducting research and insufficient training of fellow health workers, including other nurses.

- Insufficient number of nursing posts to ensure quality nursing care by registered nurses.

These obstacles were derived from the summaries of the challenges that registered nurses and supervisors were experiencing. In this study, the registered nurses were viewed as partners in various relationships, including with their colleagues, supervisors, subprofessional nurses, multisectoral team members, the researcher, patients/clients, students and non-governmental organisations. Accordingly, the recipient is expected to fulfil certain roles and functions and to possess certain characteristics in order to maintain effective relationships. In the following sections the roles of the registered nurses in local-level PHC will be discussed, followed by a discussion on the functions of the registered nurse.

\subsubsection{Roles of the recipient}

PHC nurses are part of a community of health nurses (Vlok, 1996 Stanhope \& Lancaster, 2000; Stanhope \& Lancaster, 2008; Clark 2008; Tomey, 2009; Berman et al., 2008) and their primary mission is to improve the health of the population through health promotion, the prevention of illness and injury and the protection of the public from a wide variety of biological, behavioural, socia and environmental threats. The purpose of these activities is to promote the good life in all of its physical, social, psychological, cultural and economic aspects, while focusing on caring for the aggregates. Aggregates in the context of PHC refer to sub-groups of a population who share common characteristics or health challenges, such as pregnant adolescents and the elderly. It is, thus, essential that the PHC nurses are informed about the needs of the individuals and families in a community, with the ultimate aim of improving the health of the entire population.

As regards community PHC, registered nurses apply the principles of public health in their approach to nursing care (Clark 2008, Ginger \& Davidhizar, 2008; Fraser \& Cooper, 2009; Rassool, 2009; Eshun \& Gurung, 2009; Du Toit \& Van Staden, 2009). A research study conducted by Baldwin, Lyons, \& Issel (2010), on ways in which to enhance the visibility and public awareness of public health nurses in the United States Department of Health, concluded that public health nurses should care not only for patients but also for the community. In addition, they should be aware of both communicable diseases and the safety of the environment with more emphasis on awareness rising for the community in terms of the members of the community taking initiatives in the care of their own health.

The roles and functions of PHC nurses are categorised on the basis of the primary focus of nursing care as being client-oriented, delivery-oriented or population-oriented (see figure 4).

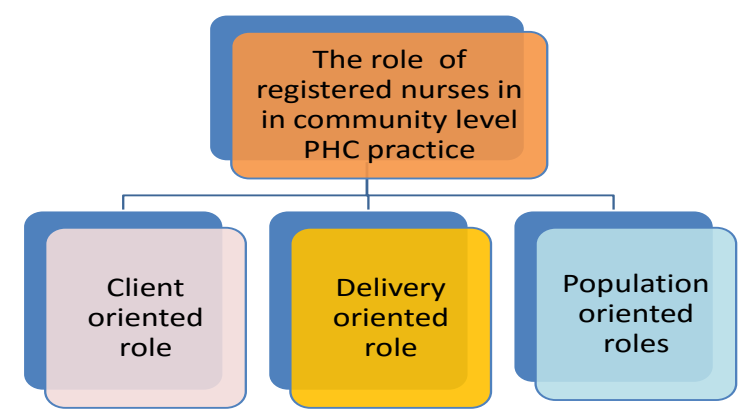

Fig. 4: The Primary Focus of Community PHC Nursing as Rendered by the Recipient

The various role functions that must be fulfilled by registered nurses as regards each role will be described in the next section, but first they are listed in the table below:

Table 1: The Role of the Recipient

\begin{tabular}{ll}
\hline Category of role & Role functions \\
\hline & Care giver \\
Client oriented & Educator \\
& Referral resource \\
& Counsellor \\
& Role model \\
& Case manager \\
& Coordinator/care manager \\
& Collaborator \\
Delivery oriented & Liaison \\
& Educator \\
& Case finder \\
& Leader \\
& Change agent \\
& Community mobiliser \\
Population oriented & Policy advocate \\
& Social marketer \\
& Researcher \\
& Educator \\
\hline
\end{tabular}

\section{Client-oriented role}

The client-oriented role involves the direct provision of services to individuals and families and, occasionally, to groups of people. It does not, however, entail the exclusive provision of populationfocused services, but instead uses services to individuals and families as one way in which to improve the health of the population. Population-focused nursing is, thus, grounded in individuals and families. The client-oriented community health nursing roles include those of caregiver, educator, counsellor, referral resource, role model, primary care provider, and case manager (Tomey, 2009; Gopee, 2008; Jones, 2007; Stanhope \& Lancaster, 2008).

Caregiver: This role involves applying the principles of epidemiology and the nursing process to the care of clients at any level individual, family, group, or community. It also includes assessing the needs of clients, making nursing diagnoses, and planning appropriate nursing interventions, including various nursing procedures, and evaluating the nursing care provided and its outcome. When these principles are applied to the care of the population, it 
entails planning programmes designed to improve health (Tomey, 2009; Jooste, 2010; Bhengu, Car, \& Carter, 2008; Stanhope \& Lancaster, 2008).

Educator: This role facilitates the learning that leads to positive health behaviour on the part of clients. However, the role also involves educating, students and health professionals, including fellow registered nurses (Berman et al., 2008; Tomey, 2009; Jooste, 2009; Stanhope \& Lancaster, 2008).

Counsellor: This role includes helping clients to choose viable solutions to their health problems. In other words, it involves helping them to utilise the problem-solving process and to decide on the most appropriate course of action.

Referral resource: This role entails the process of directing clients to the resources required to meet their needs. These resources may be other agencies that are able to provide the necessary services or the resources of information, equipment, or supplies that the clien needs and that the community health nurse is not able to supply (Gopee, 2008; Berman et al., 2008; Stanhope \& Lancaster, 2008). Role model: The role involves either consciously or unconsciously demonstrating behaviour to others who perform a similar role to the registered nurse, for example other nurses and other members of the health care team (Tomey, 2009; Gopee, 2008; Jones, 2007; Stanhope \& Lancaster, 2008).

Case manager: As case manager, the registered nurse coordinates and directs the selection and use of health care services to meet client needs, maximises resource utilisation and minimises the expense of care (Gopee, 2008; Berman et al., 2008; Stanhope \& Lancaster, 2008).

\section{Delivery-oriented roles}

These are roles designed to enhance the operation of the health care delivery system, thus resulting in better care for clients. These delivery-oriented roles include the following:

Coordinator/care manager

This role includes organising and integrating services to meet client needs in the best and most efficient manner possible. This, in turn, involves determining who is providing care to the client, where the services overlap and where gaps in the care may be occurring as well as communicating with other providers regarding the particulars of the client situation and client needs; arranging events such as meetings and conferences to disseminate information, bringing agencies together and coordinating individual client care (Tomey, 2009; Jooste, 2010; Shober, 2008; Stanhope \& Lancaster, 2008).

\section{Collaborator}

In this role the registered nurse facilitates a good working relationship among the members of the health care team. Thus, this function differs from the coordination of care services which is limited to the registered nurse's area of work (Tomey, 2009; Gopee, 2008; Jones, 2007; Berman et al., 2008).

\section{Liaison}

In terms of this role the registered nurse provides a connection, relationship or inter-communication between the various health and social agencies involved in the care of a client (Tomey, 2009; Jooste, 2009; Jones, 2007; Berman et al., 2008).

\section{Educator}

As an educator the registered nurse facilitates learning that leads to positive health behaviour on the part of clients but also provides education for students and health professionals, including fellow registered nurses (Jones, 2007; Berman et al., 2008; Stanhope \& Lancaster, 2008).

\section{Population-oriented roles}

These roles are directed towards promoting, maintaining and restoring the health of the population and include:

Case finder

This role involves identifying individual cases, occurrences of specific diseases or other health-related conditions requiring services as well as suggesting and implementing appropriate responses to each case, for example food poisoning (Fawcett \& Waugh, 2008; Stanhope \& Lancaster, 2008).

Leader
As a leader the registered nurse influences the behaviour of others and selects an appropriate leadership style. In addition, this role involves assessing the leadership needs of followers and applying the leadership style appropriate to both the followers and the situation at hand (Daft, 2010; Jooste, 2009; 2010; Jones, 2007; Berman et al., 2008).

Change agent

A change agent is a person who facilitates others to change a bad situation to a good situation and to cope with any sudden deviations from daily condition in such a way that the situation will not be too disruptive (Daft, 2010; Shober, 2008). The registered nurse in PHC serves as a change agent, working with individuals, families, groups and communities in the delivery of health care.

Community mobiliser

This role involves the sensitisation and awakening of community groups so as to enable them to identify common goals and mobilise the assets required to implement strategies that address local concerns. In addition, the registered nurse, as community mobiliser, promotes the active participation of community members in identifying and solving problems of concern (Shober, 2008; Clark, 2008; Stanhope \& Lancaster, 2008).

\section{Coalition builder}

This role involves facilitating the process of creating either the temporary or permanent alliances of individuals or groups in order to achieve a specific purpose as well as facilitating communitywide problem solving and collaboration, particularly as regards policy and programme development (Tomey, 2009).

Policy advocate

Advocacy is about finding a voice for those who are not able to speak for themselves in order to defend themselves, especially the poor, the weak or the vulnerable (Stanhope \& Lancaster, 2010; Daft, 2010; Jooste, 2010; Berman et al., 2008). Thus, as a policy advocate the registered nurse works for and argues on behalf of either policy formulation or changes in policy that influence the health of population groups.

Social marketer

As a social marketer the registered nurse uses social marketing techniques to influence the voluntary behaviour of target audiences with the aim of improving either their personal welfare or that of society (Daft, 2010)

Researcher

The role of researcher involves critically reviewing relevant research and its application to practice, identifying researchable problems, designing and conducting research studies, collecting data and disseminating research findings. The aim of this behaviour is to improve the health of the total population (Stanhope \& Lancaster, 2008; Guest \& Scullion, 2007).

\section{Educator}

This role involves facilitating the learning that leads to positive health behaviour. Thus, clients and others are provided with the information and insight that enables them to make informed decisions on health matters. In addition, this role includes educating students and health professionals, including fellow registered nurses (Jones, 2007; Berman et al., 2008).

\subsection{Qualities of the recipient}

If the recipient is to carry out his/her duties properly, then he/she should possess the following qualities:

- A sense of responsibility in terms of making contact with or involving the community in matters related to their health care through community leaders, and endeavouring to instil a spirit of cooperation in the families in the community so that they support the activities related to environmental hygiene.

- Be open to communication with supervisors about the areas in which the registered nurses feel they need support.

- Should be advocates of health promotion initiatives related to the care of adolescents and school children.

- If necessary, use private time to assess environmental issues in surrounding communities. 
- When interacting with patients, endeavour to assess the issues related to household hygiene and also socioeconomic issues.

- Develop a strong conviction that, as a professional nurse, it is possible to aspire to greater things.

- Those registered nurses in supervisory positions should take the initiative to serve as role models for their subordinates (Coetzee, \& Roythorne-Jacobs, 2007; Rily, 2008).

\subsubsection{Functions of the recipient}

Registered nurses have dependent, independent and interdependent roles and functions (Searle, Human \& Mogotlane, 2009).

These roles and functions are described in the following sections: Dependent functions

The dependent function of the registered nurse involves obeying the law which authorises her practice, as well as the relevan common and statutory laws, while remaining accountable for every function which he/she, as a professional person, carries ou and/or those functions which he/she neglects to fulfil sufficiently in his/her expected role. This expected role is based on the provisions of the Nursing Act, 2004 (Act No. 8 of 2004) and the regulations that authorise the practice of the registered nurse (Searle, 1987; Jooste, 2010; Searle et al., 2009; GRN, 1990).

As regards the elements of $\mathrm{PHC}$, a registered nurse is expected to ensure that, in her daily practice, she focuses on all the functions that should be carried out for the wellbeing of patients/clients in the catchment area he/she serves, while utilising the nursing process as a framework to guide the care rendered (Clark, 2008).

Independent functions

According to Searle (1987) and Searle et al. (2009), there are two aspects to the independent function of a registered nurse. The first aspect is related to those factors which are inherent in nursing diagnosis, treatment and care - the normal prescriptive, organisational and implementation functions of the nurse. The second aspect is related to the manner in which a registered nurse performs her duties as a registered nurse, irrespective of whether these are independent or interdependent functions. This, in turn, means that the registered nurse remains totally accountable and responsible for her actions, while the doctor may not be held accountable for the actions of the registered nurse provided that the doctor has ensured that his/her prescription was clear. This requires that a registered nurse ensure that her knowledge and skills are up to date as regards her practice. In addition, the registered nurse will refuse to participate in illegal and/or unethical practices (Tomey, 2009; Jooste, 2010; Barnald \& Locsin, 2007; Searle et al., 2009).

Once a registered nurse has accepted the prescription or direction from the doctor or other member of the health care team, she has made a commitment in terms of interdependent action and has a duty to carry out this action, while accepting full responsibility for her actions (Tomey, 2009; Searle et al., 2009).

The fulfilment of the PHC role functions requires that the registered nurse carry out all the duties in this regard and, based on the nursing process, maintain a good working relationship with the doctor and other members of the health team, as well as ensuring that the rights of the patients/clients are respected (Shober, 2008). Interdependent functions

The interdependent function refers to the interrelationship between the registered nurse and the other members of the health team in the interests of the patient and relates primarily to the interdependence of the registered nurse and the doctor, the nurse and the supplementary health service personnel, and the nurse and the pharmacist. The nurse is neither a servant nor a subordinate of the doctor attending a patient, except in the case of the medical superintendent and his/her deputies or others who may have been placed in a service position in direct authority over the registered nurse. However, in a doctor-nurse-patient relationship, the relationship is a collegial one between the doctor and the registered nurse, with both being responsible for the patient and his/her safety. As a registered professional practitioner the registered nurse is personally accountable to the registration authority - the Namibi- an Nursing Council - to the patient, and to society under the law of the Republic of Namibia. In addition, the registered nurse is administratively responsible to his/her employer (Searle, 1987; Tomey, 2009; Searle et al., 2009; Nursing Act No 8 of 2004; GRN, 1990).

This responsibility of the registered nurse, as mentioned above, is also true for PHC delivery. The nurse has a specific coordinating function to ensure that the patient is rendered all the services he/she needs from the various members of the health team. In addition, the registered nurse is accountable for both his/her acts and omissions regarding this responsibility, while the doctor is not accountable for the acts carried out by the registered nurse. However, the doctor is expected to ensure that his/her prescriptions, instructions or requests are recorded, clear, valid, within the law and that the person to whom he/she has entrusted his/her prescriptions or instructions understands them and is able to implement them in the best interests of the patient (Searle, 1987; Tomey, 2009; Jones, 2007).

In nursing practice, the nurse shares the instrumental and expressive roles with the doctor while, as regards the nurse-doctorpatient relationship in the health care continuum, the work of the doctor and the nurse may overlap. Both the doctor and the nurse have an instrumental as well as an expressive role. The instrumental role is concerned primarily with the acquisition of knowledge regarding the health situation, the evaluation of such knowledge, and the utilisation of this knowledge in the search for a possible solution to the problem. In other words, this role involves observation, diagnosis, therapeutic planning and intervention and the selection, on scientific grounds, of the nature and extent of the therapeutic intervention. On the other hand, the expressive role is more concerned with the establishment and maintenance of an extensive and effective therapeutic environment and includes administrative aspects relating to the establishment of a safe, restful, pleasant and purposeful environment, with special emphasis on the exclusion of medico-legal hazards, and the ensuring of maximum physical and psychological safety.

The expressive role aims to reduce patient tension by accepting the individual as he/she is, with full recognition of his/her individuality, fears, hopes and recovery potential and by supporting the patient through the basic nursing care, thus demonstrating the concern of the nurse for the patient. In addition, this role involves identifying the health needs of the patient correctly, obtaining appropriate assistance from other health professionals and carrying out all therapeutic interventions and nursing care in the right manner (Tomey, 2009; Bhengu et al., 2008; Barnald \& Locsin, 2007; Searle et al., 2009). This should include an assessment of any social pressure and the way in which this social pressure may be contributing to psychological distress in the patient, thus influencing his/her health negatively in the long run (Pilgrim, 2010; Fawcett \& Waugh, 2008).

The doctor's role is primarily instrumental and, to a lesser extent, expressive. On the other hand, the role of the registered nurse is primarily expressive and, to a lesser extent, instrumental, except where the registered nurse is functioning in the role of either doctor or pharmacist, in the absence of one or both of these health practitioners. In certain instances, tasks that should be carried out by the doctor or the pharmacist are performed by a registered nurse. However, it is emphasised that, whatever instrumental role the registered nurse carries out in the absence of either the doctor or the pharmacist or other members of the health care team, it is essential that the registered nurse bear in mind that she is fulfilling this role as a nurse and never claim to be a doctor or otherwise (Tomey, 2009; Geyer et al., 2009; Searle et al., 2009).

Registered nurses should always remember not to neglect the expressive role, as inefficiency or negligence in the expressive function gives nursing a poor image. On the other hand, fulfilment of these roles makes nursing a caring profession. The varying roles of the registered nurse, with so much more emphasis being placed on the instrumental role, and so much of the expressive role being delegated to semi-skilled nurses, will, inevitably, have an adverse 
effect on the image of nursing in the future, if not properly addressed (Jooste, 2010; Searle et al., 2009).

\subsubsection{The professional characteristics that the recipient should possess}

\section{Curiosity}

Curiosity refers to a strong desire to know about something while intellectual curiosity refers to the act of using a person's ability to think in a logical way and to understand things (Oxford Advanced Learner's Dictionary, 2010). As leaders in the nursing profession, it is essential that registered nurses make use of this trait to enable them to take risks. In addition, curiosity facilitates change and will teach the registered nurse not to spend his/her time doing things based on facts and not on their own feelings rather than wasting time on matters that will not work (Carroll, 2006; Searle et al., 2009).

Enthusiasm

Enthusiasm may be defined as a strong feeling of excitement and interest in something and as a desire to become involved (Oxford Advanced Learner's Dictionary, 2010). A registered nurse should, thus, be passionately enthusiastic about future possibilities and inspire his/her fellow nurses and draw them into a common effort to make those future possibilities a reality (Carroll, 2006; Searle et al., 2009).

Motivation

Motivation is the reason why an individual behaves as he/she does. It may also be defined as the will to do something, especially anything that involves hard work (Oxford Advanced Learner's Dictionary, 2010). In the context of this study, motivation in volves the registered nurse having a strong will to do everything possible so as to render the best PHC service delivery. Individual actions are guided by personal goals and it is incumbent on the registered nurse to strive for excellence and to be committed to the realisation of goals (Stanhope \& Lancaster, 2010; Tomey, 2009; Searle et al., 2009; Smit et al., 2007). However, the advanced community nurse should be regarded as a facilitator and should not be expected to do everything.

Responsibility

Responsibility is defined as a duty to deal with or take care of something so that the individual concerned may be blamed if something goes wrong (Oxford Advanced Learner's Dictionary, 2010). In other words, this concept means to act based on the expectations in a particular situation and it may be applied to an individual to whom some duty or responsibility has been delegated by a person in authority and who will be subject to a penalty in the case of a default (Searle, 1987; Tomey, 2009; Searle etal., 2009).It is, thus, essential that the registered nurse take responsibility for his/her own learning and for the learning of his/her subordinates/fellow workers (Clark, 2008; Geyer et al., 2009; Bhengu et al., 2008; Searle et al., 2009; Coetzee et al., 2007).

Accountability

Accountability is defined as a status in terms of which an individual must take responsibility for his/her decisions or actions and also be expected to explain these decisions or actions when asked to do so (Oxford Advanced Learner's Dictionary, 2010). In other words, accountability means that it is incumbent on the person to whom the responsibilities have been assigned to account for her/his actions. In terms of PHC, the registered nurse is expected to account for his/her acts and/or omissions, as must any other nurse in practice (Searle, 1987; Tomey, 2009; Geyer et al., 2009; Searle et al., 2009).

Good interpersonal relations

The interpersonal dimension of nursing includes certain affective elements and interaction skills, as well as the ability to collaborate and communicate effectively with others, as the situation requires (Clark, 2008; Tomey, 2009; Smit et al., 2007; George, 2011). It is, thus, essential for the registered nurse in PHC to employ these skills and abilities effectively in his/her interactions with other members of the health care team, as well as the patients and their families (Ivancevich et al., 2008; Daft, 2010; Geyer et al., 2009; Searle et al., 2009).

Bearing in mind that the PHC nurse is a community health nurse, Clark (2008) adds more attributes (characteristics) that a community health nurse should possess. These include population consciousness, orientation to health, autonomy, creativity, continuity, collaboration, intimacy and variability.

Population consciousness

As a community health nurse, a nurse in PHC should possess a consciousness beyond the needs of and services to individual clients and families and always be aware of the way in which the health of an individual relates to the health of the total population and vice versa. In addition, she should identify specific family problems and deal with them accordingly as well as making a constant effort to enhance the health and socioeconomic conditions of the population he/she is serving (Clark, 2008, p. 10).

Orientation to health

Although community health nurses frequently help clients to resolve existing health problems, their major goal is to promote the client's highest possible level of physical, emotional and social wellbeing. Health promotion, as practised by community health nurses, encompasses both the promotion of self-care behaviours on the part of the client and advocacy for the social and environmental conditions that promote health (Stanhope \& Lancaster, 2010).

\section{Autonomy}

Autonomy refers to the ability to make decisions independently and to engage in constructive activities. It is also referred to as self-directedness. In view of the fact that community health nursing care is typically provided in the client's environment, the active participation of the client is required, while the community health nurse should anticipate and foster the active involvement of the community at large in the determination of health policy and the planning of service delivery. Community health nurses also exercise a considerable degree of professional autonomy by relying on their own judgement to decide on an appropriate course of action as, in some situations, they may be the only available provider of health care (Stanhope \& Lancaster, 2010; Searle et al., 2009).

\section{Creativity}

Creativity refers to the skill and ability to think through a problem and to find a way in which to be productive, even in a resourceconstrained setting (Tomey, 2009). Community health nurses are dealing with increasingly complex problems at the individu$\mathrm{al} /$ family and the population levels and, thus, it is essential that they possess creativity in order to be able to deliver services, even in a resource-constrained context (Mank, 2006; Geyer et al., 2009; Searle et al., 2009).

Continuity

Continuity refers to the opportunity to be engaged with somebody, or with an activity, for a sufficiently long time (Stanhope \& Lancaster, 2010). Community health nurses must have the flexibility to work with clients until both parties feel that the services are no longer required. As a result of the extended nature of this relationship between client and community health nurses, these nurses are able to evaluate both the long-term and short-term effects of nursing interventions for the individual, family or the community (Clark, 2008; Berman et al., 2008; GRN MOHSS, 1992, Official Primary Health Care/Community Based Health Care Guidelines). Collaboration

Collaboration refers to working together in a relationship involving different sectors with similar objectives (Mank, 2006; Daft, 2010). Community health nurses are often engaged in collaborative efforts with individuals, the community or sectors as regards identifying community needs and planning the services required to meet those needs (Daft, 2010; Clark, 2008, p. 11; Tomey, 2009; Searle et al., 2009).

Intimacy

Intimacy refers to a state of being when one has both the opportunity and the ability to establish a close relationship and a feeling of togetherness with another person or a group of persons - a 
common occurrence in community nursing practice, including local-level PHC practice. This, in turn, enables the registered nurse at this level to obtain a more accurate idea of the factors affecting the client's health, unlike in hospital settings where the client's behaviour may be modified by the unfamiliarity of the health care environment. Thus, this implies that the PHC nurse should carry out his/her activities within the community in a more flexible manner, as the situation may require (Clark, 2008).

Variability

Variability refers to the fact that one is able to deal with different situations and persons or groups of persons in a meaningful way (Mank, 2006). This characteristic is important for PHC nurses because they deal with diverse clients at different levels (individual, family or population group) and from different ethnic backgrounds in a wide variety of settings. This variability requires a broad knowledge base to enable the individual concerned to adapt effectively to this diversity and to be able to prevent or alleviate the health problems of groups of people as well as individual members of society (Berman, Snyder, Kozier \& Erb, 2008; Clark, 2008).

Professional values of the recipient

Searle (1987), Hess and Cameron (2006), Tomey (2009), Jooste (2010) and Searle et al. (2009) are all of the opinion that the nurse should be assisted to acquire a sound professional philosophy about her work and the meaning of human needs. This is deemed necessary so that the nurse will view nursing as a caring profession and not merely a job. In addition, this philosophy should remind her that he/she should never be dominated by his/her emotions, and should also instil the following values:

Poise

Poise refers to a calm and confident manner with control over one's feelings and behaviour (Geyer et al., 2009).

Courage

Courage refers to the ability to face pain or opposition, without showing fear (Oxford Advanced Learner's Dictionary, 2010; Daft, 2010; Tomey, 2009; Amos et al., 2008).

\section{Faith}

Faith refers to a trust in somebody's knowledge or a belief that what one does as a person is correct (Oxford Advanced Learner's Dictionary, 2010; Tomey, 2009; Geyer et al., 2009).

\section{Understanding}

Understanding refers to the knowledge that an individual has about a particular subject or situation (Oxford Advanced Learner's Dictionary, 2010). As regards PHC, understanding will enable the registered nurse to function independently as a health care professional (Searle et al., 2009).

Caring

Caring is defined by the Oxford Advanced Learner's Dictionary (2010) refers to being kind and helpful and showing that one cares about other people. Thus, a caring profession is explained as an occupation that involves looking after or helping other people.

Nursing is a caring profession and, as such, requires that the registered nurse in PHC demonstrate care and concern for individual clients and for the community at large. It is, thus, important for the registered nurse to remain close and warm and to use the sense of touch when dealing with clients, as these are some of the qualities that give nursing its caring nature as a profession. These attributes should, therefore, also be fostered in PHC (Mank, 2006; Stanhope \& Lancaster, 2010; Tomey, 2009; Geyer et al., 2009; Searle et al., 2009).

\subsubsection{Concluding statements for the recipient}

Registered nurses practice within organisations that have goals, values and missions. Integration into an organisation's value system and identification with the organisational goals mean that employees should execute their roles and functions in such a way as to develop feelings about the adequacy and quality of their performance, similar to the goals, values and missions of the organisation they work for. In view of the fact that the study has concluded that certain roles and functions are not executed effectively in PHC delivery, it is clearly necessary to strengthen the role and function of the registered nurse (recipient)

The scope of practice of a registered nurse in Namibia is provided for through either a government notice or a regulation known as the "Scope of Practice of People Registered as Nurses, Midwives and Accoucheurs". These regulations indicate both the areas of functions and omissions that are punishable by law.

\subsection{Procedure}

The development of strategies is based on the problems which have been identified as a result of research evidence. In addition, strategies should be formulated in accordance with specific principles while taking into account the challenges in the environment in which the strategies will be implemented as well as the risks and benefits involved (Rossow, Le Roux, \& Groeneward, 2003; Amos et al., 2008).

In this study the nursing process framework facilitated the development of strategies to be utilised by both registered nurses and their supervisors in the fulfilment of their PHC roles and functions. The nursing process has features of participative management, which emphasises the involvement of workers in planning and decision making in their daily work (Muller et al., 2006).

It emerged from the results of this study that the purpose of the strategies envisaged is to support registered nurses in their roles and functions of PHC practice by utilising the nursing process, while embracing participative management as a tool in order to improve the quality of nursing practice in PHC.

Table 2 below presents the stages and steps involved in the development of the strategies in this study while figure 5 depicts the procedure.

At the operational level, registered nurses are expected to function independently within their scope of practice and by utilising the nursing process. The strategies address the areas in local-level PHC practice that require support as they were revealed by the study findings.

Table 2: The Stages and Steps Involved in the Development of Strategies in this Study

\begin{tabular}{ll}
\hline Stages & Steps \\
\hline & $\begin{array}{l}\text { Step 1: Research findings on how registered nurse } \\
\text { utilise the nursing process in their daily PHC practice } \\
\text { Step 2: Identification of challenges faced by regis- } \\
\text { tered nurses when utilising the nursing process in } \\
\text { daily PHC practice }\end{array}$ \\
$\begin{array}{l}\text { Step 3: Reasoning map/identification of dynamics } \\
\text { and strategies to address challenges }\end{array}$ \\
$\begin{array}{l}\text { Step 4: Setting of objectives according to which } \\
\text { strategies were formulated }\end{array}$ \\
$\begin{array}{l}\text { Step 5: Description of strategies } \\
\text { Stage 2: Valida- }\end{array}$ \\
$\begin{array}{l}\text { Step 6: Validation of the relevance of strategies by } \\
\text { experts in PHC }\end{array}$ \\
\hline
\end{tabular}

The tools that are needed for successful utilisation of the nursing process in local-level PHC include communication, interactive decision making, shared governance, interpersonal relationships, and organisational transformation (Ginger \& Davidhizar, 2008).

\subsubsection{Concluding statement for the procedure}

It is hoped that the strategies will enhance the role and function of the registered nurse in the utilisation of the nursing process when providing PHC services.

The tools to use when utilising the nursing process, which include communication, interactive decision making, shared governance, organisational transformation and empowerment, will increase both job satisfaction and self-competence as well as bringing about an improvement in the standard of practice. 


Research find-
ings and identi-
fication of chal-
lenges

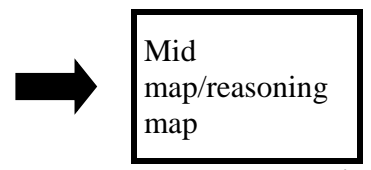

Fig.

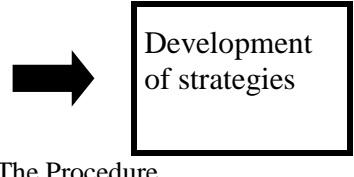

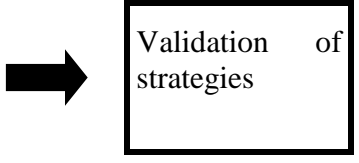

\subsection{Context}

For the purpose of this study, the context was defined as the environment of the health facilities in which PHC is delivered outside of the hospital, the legal framework in which the services are delivered, and the policies and procedures governing these services (see figure 6).

The context of this study included health clinics, health centres and outreach points, all of which are considered to be operationallevel PHC facilities in the context of the district health care delivery system. In these health facilities, the fulfilment of the roles and functions of registered nurses in PHC is planned according to the health policies, such as the"Official National Policy Guidelines on Primary Health Care/Community Based Care" and other policy documents that direct that PHC services are delivered as an integral part of the health care system for the whole country and that it is incumbent on registered nurses in local-level facilities to observe the existing chain of command from central level downwards (GRN MOHSS, 1992; 1995; Hopwood, 2008).

In health care organisations, it is essential that one be aware that all countries have organisational structures and political administrative structures comprising of three hierarchical levels, namely, central, intermediate and local, and also a health development framework that fits the linkages between these hierarchical facilities and health and socioeconomic development. The aim of having such organisational structures is to create channels of communication and chain of commands so as to ensure that every health care provider knows where to report and to whom he/she is accountable (Blass, 2009; Daft, Kendrick \& Vershinina, 2010; Searle et al., 2009).
Health-related activities are organised for individuals, families and communities and are managed within local government areas, zones or districts. The structures and institutions at the local, intermediate and central levels provide three types of overlapping support for the community health initiatives, namely, operational, technical and strategic management support. It is at the local level (operational level) that all resources are pooled for the implementation of PHC (GRN MOHSS, 1995).

Technological options are selected at the intermediate level and, if necessary, are adapted before being applied to PHC; at the same time, at the central level strategic choices are made for the utilisation of the available resources as regards the purchase of traditional or modern technologies. It is also at the central level where management improvement efforts are initiated and/or sustained. However, other health-related sectors and universities, as well as non-governmental organisations, all assist in strengthening the health services at all three levels.

In Namibia the levels of health care delivery include:

- Local/community level (health centres/clinics/outreach points). This level is the operational level for registered nurses in local-levelPHC.

- Districts with their clinics and health centres as well as other health and non-health related sectors that contribute to or have a stake in PHC delivery.

- Intermediate level which is also referred to as the regional level. This level provides all the technical support forthe districts.

- Central level - the national level - as the (GRN MOHSS, 1995).

Figure 6 depicts the context.

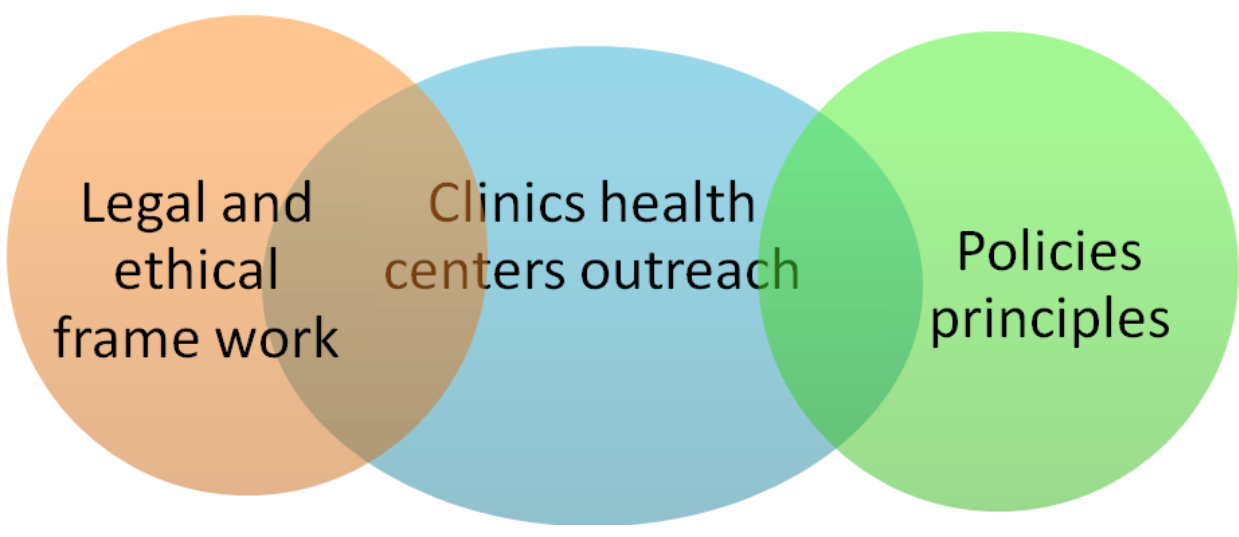

Fig. 6: The Context.

The Directorate of Primary Health Care is responsible for policy making and channels all output through the regional level to reach the operational level. It is expected that the health services at the operational level should be provided in such a way that the proper channels of communication and chains of commands are adhered to. As regards the participants in this study the chain of command entails the following: orders should flow from the national level to the regions and from the regions to the districts and from district level to health facility level. The response from the bottom will follow the same channel upwards. Even with the development or utilisation of the strategies to be discussed in the separate papers, all these levels should be involved and, in the interests of reinforcement, the order should be generated from national level down through the regions to the districts and then to the individual health facilities.
The first level of contact with the district health services include individuals, families and communities, while the second level in this regard is the clinic or health centre and, at the third level, the district hospital. For the purpose of this study the focus will be on the first level of the district health services, namely, at community level, together with the clinics and health centres because the functions expected of the registered nurses at all these levels are the same (GRN MOHSS, 1995).

In Namibia, all patients seeking health care have the right to access to care which, in turn, is provided in accordance with the PHC approach. These rights are detailed in the patient charter of rights. Registered nurses fulfil their roles and functions in PHC facilities according to the provisions of the Nursing Act 2004 (Act no. 8 of 2004), as outlined in the Government Gazette of the Republic of Namibia. 
The Constitution of the Republic of Namibia (The Constitution of the Republic of Namibia (GRN, 1990) has declared health to be a fundamental right of every Namibian/person seeking health care in Namibia. The government acknowledges that it is essential that everybody in the country be in a good state of health. However, in view of the fact that it is not possible to take for granted that health care services will be made accessible to everybody, as is the intention of the government, the right to basic health services has also been included in the list of fundamental human rights enshrined in the Constitution of the Republic of Namibia. This, in turn, will enable the public/community members to demand their right to health (The Constitution of the Republic of Namibia (GRN, 1990).

As was mentioned above, the patient charter of rights defines all the rights a patient has when seeking health care services at state health facilities. It also suggests the procedures to be followed should either a patient or family member feel that her/his rights have been violated and that he/she would, therefore, like to launch a complaint in this regard.

Both the Nursing Act 2004 (Act No 8 of 2004) and the scope of practice are legal documents that direct the conduct of registered nurses and other groups of sub-professional nursing categories in Namibia in their provision of nursing care. These documents provide clear outlines regarding the criteria for admission to nursing studies, as well as the minimum requirements for training courses for registered nurses, the duration of such training courses, every training/education programme, and the curriculum content for each education programme, the pass/promotion criteria as well as the scope of practice for those registered. The Nursing Council is a regulatory body for the nursing profession that serves to protect the public from both unethical practices and malpractice on the part of registered nurses, as well as protecting the public from harmful practices, including the practice of the profession by individuals who are not registered (Nursing Act No 8 of 2004).

\subsubsection{Concluding statement for the context}

The context in which PHC services are delivered comprises clinics, health centres and outreach posts and they are offered within the existing legal and ethical framework in terms of which PHC should be delivered. Cooperation, shared decision making and communication will enable registered nurses to fulfil their roles and functions in local-level PHC.

\subsection{Dynamics}

Dynamics may be defined as the way in which people or things behave and react to each other in a particular situation (Oxford Advanced Learner's Dictionary, 2010). As such, dynamics refer to motivating forces in any field (Muller, 2001). Regarding the fulfilment of PHC role functions in local-level health facilities, the dynamics may be identified as the interactions between registered nurses and their patients/clients and other members of the multidisciplinary health team about the way in which registered nurses interact with/relate to their environment as well as the difficulties/challenges posed by the lack of material and human resources required for the better fulfilment of the PHC role functions (see figure7).

In figure 7, the two arrows from the upper square (black) leading into the two separate compartments, which are orange and pink, indicate that the challenges fall into two main groups, namely, areas where the nursing process is not adequately utilised to address PHC issues and managerial constraints. An asterisk indicates that the challenge is applicable to both groups of challenges.

The role and function of the registered nurse in PHC delivery is based on the PHC services, with the nurses utilising the nursing process to execute their roles and functions. However, it is not possible to utilise the nursing process in a vacuum and, as already indicated, there are steps to be followed in the process and the presence of certain dynamics which influence the utilisation of the nursing process.
In addressing these challenges, the dynamics include aspects such as interactive decision making, shared governance, organisational transformation and empowerment. Thus, cooperation and interaction between nurse supervisors and registered nurses are necessary if an environment (context) is to be created that is conducive to the nurses' effective execution of their roles and functions as regards the following PHC services: water and sanitation and other environmental health promotion services; health education and communication, including outreach services; nutrition and food supply; community diagnosis and care and management support or administrative functions, including research as a management tool in nursing.

A shortage of registered nurses and a lack of transport, as well as heavy workloads were pointed out as factors influencing the fulfilment of registered nurses' roles and functions in PHC.

A shortage of nursing staff in the face of heavy workloads is associated with overworked nursing staff and a tendency to develop burnout. This, in turn, leads to poor quality of the nursing services provided. A lack of necessary resources, such as transport, is discouraging for health care providers, as it renders registered nurses unable to fulfil their outreach functions. The role and function of the registered nurse to provide PHC services within the framework of the nursing process encompasses aspects such as providing services based on the elements and principles of PHC and applying PHC management skills in the process of care delivery (Booyens, 1999; Morrison, 2008; Tomey, 2009; Geyer et al., 2009).

The challenges, as indicated in figure 7, are largely concerned with PHC management.

Participative PHC management involves dynamic interaction between the supervisor and the registered nurses with the aim of creating an environment that is conducive to the effective execution of the registered nurse's role and function in PHC. The idea of participative management is consistent with the nursing process, which emphasises interaction and communication.

Facilitating this type of environment refers both to adequate support and to the interpersonal relations that promote PHC service delivery and ensure that the service being rendered addresses all the elements of PHC, namely:

- Environmental health

- Safe water and sanitation

- Provision of essential drugs provision

- Housing

- Treatment of common diseases and injuries

- Health education

- Control of endemic diseases

- Mother and child health, including family planning

- Nutrition

- Immunisation against preventable diseases

Supporting the registered nurse in the execution of his/her role and function with regard to PHC services delivery refers to adequate support as regards the application of the nursing process in the assessment and execution of services related to water and sanitation and other environmental health promotion services; health education and communication including outreach services; nutrition and food supply; community diagnosis and care and management support or administrative functions, including financial management, human and physical resource management and research activities.

In addition to support, human and physical resources are required if the registered nurses are to execute their roles and functions in terms of the framework of PHC. The tools that are required for the successful utilisation of the nursing process in addressing the challenges at community and local-levelPHC include communication, shared governance, organisational transformation and empowerment (Daft et al., 2010; Amos et al.,2008; Geyer etal., 2009; Ginger \& Davidhizar, 2008; Searle et al., 2009). 


\subsubsection{Concluding statement for dynamics}

Support for participation and collaboration in the provision of $\mathrm{PHC}$ by registered nurses is required in order to create an environment that is conducive to the registered nurse fulfilling his/her role and function by utilising all the steps of the nursing process, namely, assessment, diagnosis, planning, implementation, evaluation and record keeping. Also, support from the supervisors is necessary in order to enable registered nurses to participate in interactive decision making, shared governance, organisational transformation and empowerment through communication.

If the roles and functions of registered nurses are to be adequately fulfilled in their daily practice regarding the provision of PHC services, it is essential that strategies and action plans need be developed and implemented, and based on overcoming the list of challenges that have been identified above.

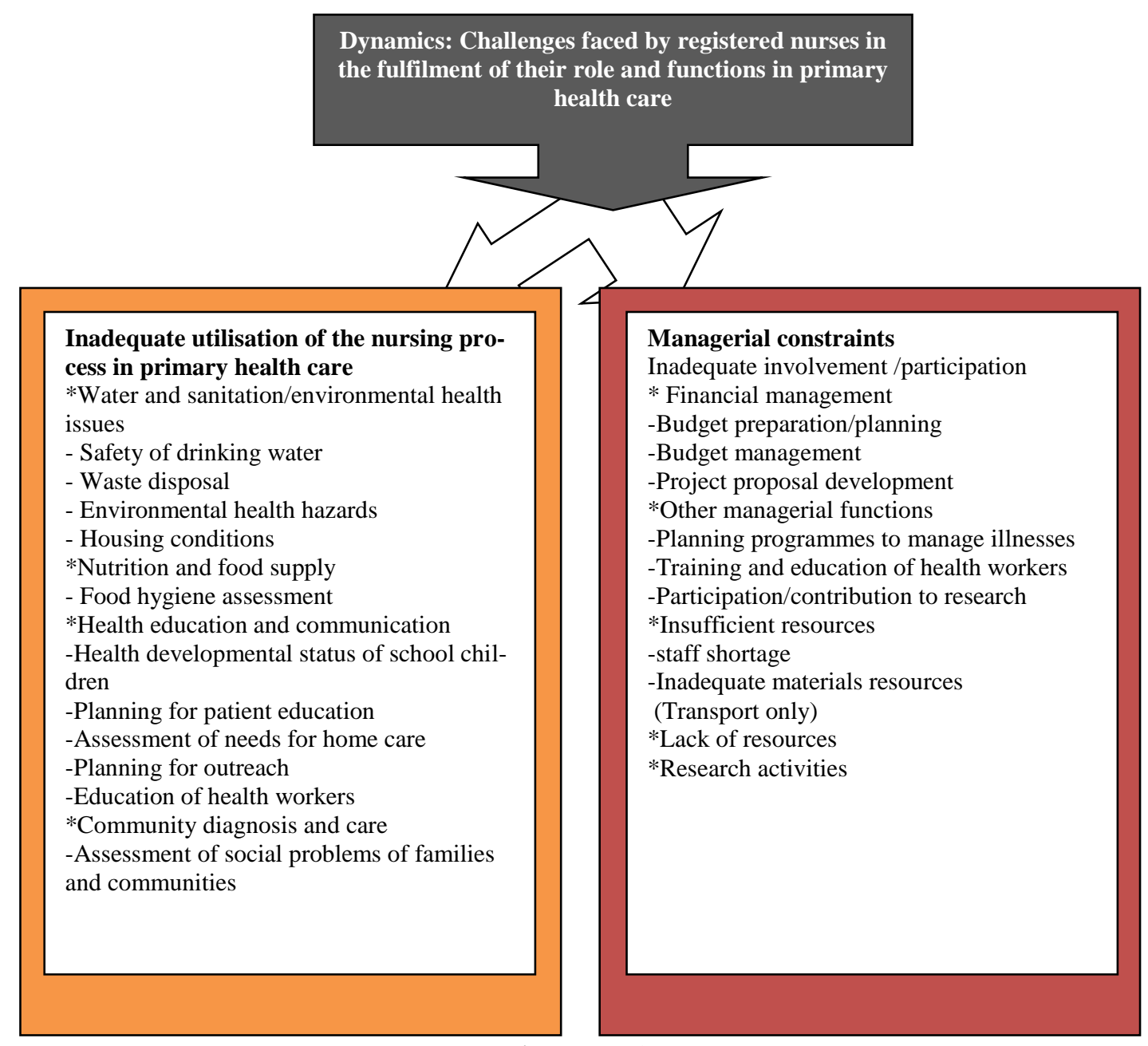

Fig. 7: Dynamics.

\subsection{Terminus (outcome)}

Terminus refers to the end result of a study (see figure 8). In this research study these end results emanated from the solutions found for the challenges encountered by registered nurses in their daily practice in local PHC facilities. It is hoped that these solutions will enable both these registered nurses and their supervisors to fulfil their PHC nursing roles and functions sufficiently.

The main purpose of the study was to scrutinise the reasons why some of the role functions of the registered nurses in PHC community/local-level facilities were not being sufficiently fulfilled, particularly in the areas of water and sanitation as well as other environmental health-related issues; health education and health communication, including outreach, nutrition and food supply; aspects of community diagnosis and care and management or administration, including research, education of health workers and outreach services. These are the areas of challenge which were identified by the results of this study.

Thus, the researcher who is an advanced community health nurse is obliged to facilitate participative management so as to ensure registered nurses and their supervisors in local-level PHC practice execute their roles and functions effectively. 


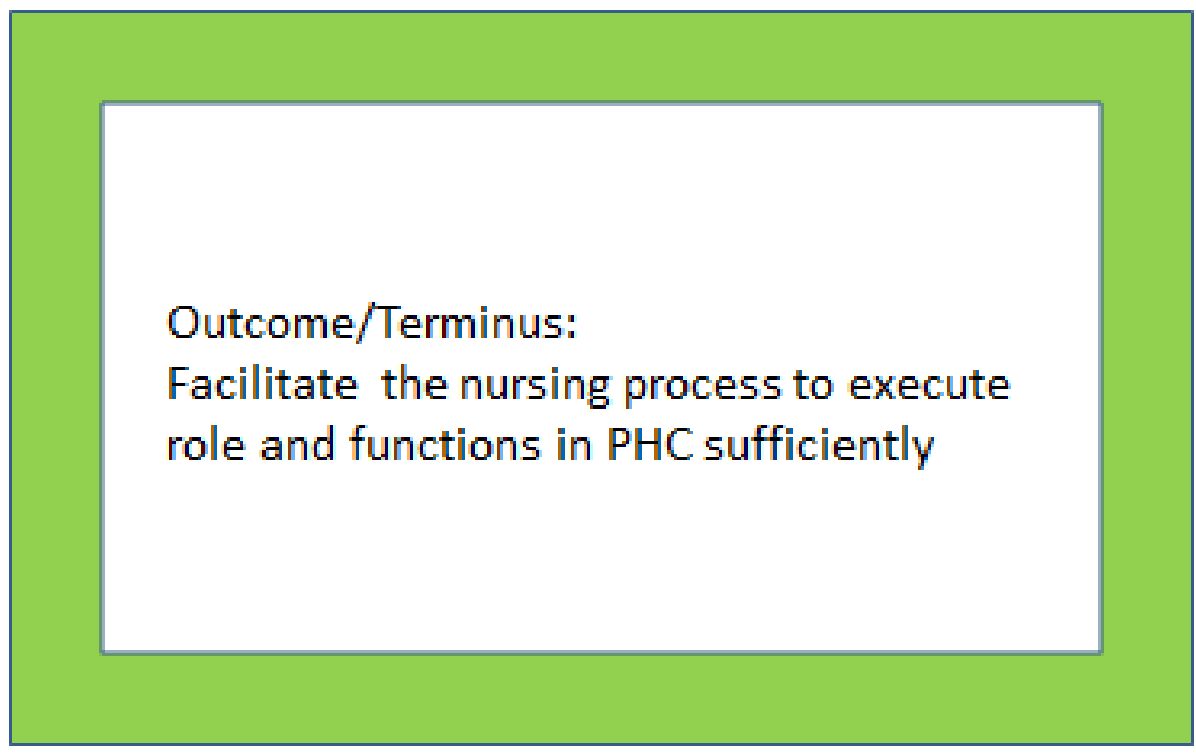

Fig. 8: Outcome/Terminus.

Both registered nurses who practise in local-level PHC facilities and their supervisors are faced with certain challenges that make it difficult for them to fulfil all the roles expected of them.

Nevertheless, the finding of this study indicate that most of the other role functions in this same area of practice were either well or moderately done, despite these challenges, is encouraging in terms of holding out the hope that these PHC nurse practitioners will also be able to enhance the fulfilment of the role functions that were not sufficiently fulfilled if they are provided with the necessary support and advice, particularly as regards written strategies that may serve as references in their daily practice. The registered nurses should be able to identify specific areas of challenges in their daily PHC practice and relate these challenges to guidelines on how these challenges may be dealt with better.

It is essential that registered nurses who work in local/community level PHC facility be prepared to teach other registered nurses and fellow health workers, as well as patients and families, how to keep abreast of PHC delivery by promoting health and preventing diseases, especially through the maintenance of a safe environment. In addition, the registered nurses should advocate for those resources that will make possible the provision of essential services, including an adequate number of registered nurses and transport facilities The registered nurses should also be involved in the planning and management of the PHC services while the research knowledge and practical skills of registered nurses need to be strengthened so as to enable them to fulfil their PHC role functions in accordance with the specific needs of a specific community.

\subsubsection{Concluding statement for the terminus}

It is essential that registered nurses working in local/community level PHC practice be supported if they are to fulfil all the expected role functions of a registered nurse at this level. It is, therefore, necessary for them to be provided with a set of strategies in terms of which those functions that require urgent actions may be better fulfilled. However, it is acknowledged that there were functions that were either well or moderately done. In addition, it is important that the registered nurses bear in mind a broader picture of the community and, thus, that they take into account the way in which individual health or ill health may be related to the health of the population as a whole.

\section{Conclusion}

In this paper, the conceptual framework for developing strategies, which was based on the theory of Dickoff et al. (1968), was discussed. The role of the agent, who is an advanced community health nurse, educator and researcher, was also discussed. It emerged that this role as agent involved facilitating the development of strategies to support the role and functions of the registered nurses in local-level PHC. The recipients in this study, who were both the registered nurses who work in local-level PHC and their supervisors, have the role to improve the functions that were not sufficiently fulfilled according to the results of this study. They observe the proposed strategies to enhance practice in the areas of concern, but they have to decide whether they have to adopt the strategies proposed or not.

The procedure is about the development of strategies to support the roles and functions of the registered nurse in local-levelPHC. The context is state clinics, health centres and outreach posts were PHC is implemented. The dynamics are the challenges that have been identified and which should be addressed by the strategies that are to be developed. The outcome is the end result of the process. It is also referred to as terminus. These strategies will be discussed in the different paper.

\section{Acknowledgement}

The researchers would like to express their appreciations to the following institutions and indiviaduals: University of Namibia for the financial and technical support; The Minstry of Health and Social Services (MOHSS) in Namibia for granting permission for this study to be carried out as well as for technical support; All the registered nurses who work in the local Primary Health Care facilities in the thirteen regions for the information they provided which helped to make this study happen.

\section{References}

[1] Amos, T., Ristow, A., Ristow, L., \& Pearse, N. (2008).Human resource management (3rd ed.). Cape Town, South Africa: Juta.

[2] Baldwin, K. A., Lyons, R. L., \& Issel, L. (2010).Creating a brand image for public health nursing.Public Health Nursing. A Journal of Population Based Nursing, 28(1), 57-67. http://dx.doi.org/10.1111/j.1525-1446.2010.00899.x. 
[3] Barnald, A., \& Locsin, R. (2007).Technology and nursing practice, concepts and issues. New York, USA: Palgrave Macmillan.

[4] Berman, A., Snyder, S. J., Kozier, B., \& Erb, G. (2008).Kozier \& Erb's fundamentals of nursing: Concepts, processes and practice (8th ed.). New Jersey, USA: Pearson, Prentice Hall.

[5] Bhengu, B., Car, M., \& Carter, C. (2008). Acute care: Clinical assessment and treatment of acutely ill patients. Professional nurses series. Cape Town, South Africa: Juta.

[6] Blass, E. (2009). Talent management. London, UK: Palgrave Macmillan. http://dx.doi.org/10.1057/9780230233522.

[7] Booyens, S. W. (1999). Dimensions of nursing management (2nd ed.). Cape Town: Juta

[8] Carrol, P. (2006). Nursing leadership and management: A practical guide. Australia. Thomson Delmar Learning.

[9] Clark, M. J. (1996). Nursing in the community (2 $2^{\text {nd }}$ ed.). USA: Prentice Hall.

[10] Clark, M. J. (2008). Community health nursing: Advocacy for population health $\left(5^{\text {th }} \mathrm{ed}\right.$.). USA: Prentice Hall.

[11] Coetzee, M. \& Roythorne-Jacobs, H. (2007).Career counseling and guidance in the workplace. Cape Town, South Africa: Juta.

[12] Daft, R. L. (2010). Understanding the theory and design of organizations (10th ed.). Australia: South-Western Cengage Learning.

[13] Daft, R., Kendrick, M., \& Vershinina, N. (2010). Management. UK: South-Western Cengage Learning.

[14] Dickoff, J., James, P., \& Wiedenbach, E. (1968). Theory in a practice discipline. Part 1: Practice-oriented theory. Nursing Research, 17(5), 415-435. http://dx.doi.org/10.1097/00006199-196809000$\underline{00006}$

[15] Du Toit, D. A., \& Van Staden, S. J. (2009). Nursing sociology (4th ed.). Pietermaritzburg, South Africa: Van Schaik.

[16] Eshun, S., \& Gurung, R. A. (2009).Culture and mental health: Sociocultural influence, theory, and practice. London, UK: Blackwell. http://dx.doi.org/10.1002/9781444305807.

[17] Fawcett, B., \& Waugh, F. (2008). Addressing violence, abuse and oppression: Debates and challenges. New York, USA: Routledge, Taylor \& Francis.

[18] Fraser, D. M., \& Cooper, M. A. (2009).Myles textbook for midwives: The world's favourite midwifery textbook! (5th ed.). London, UK: Churchill Livingstone, Elsevier.

[19] George, J. B. (2011). Nursing theories: The base for professional nursing practice (6th ed.). New York, NY: Pearson.

[20] Geyer, N., Mogotlane, S., \& Young, A. (2009). Juta's manual of nursing, Vol. 1 (2nd ed.). Cape Town, South Africa: Juta.

[21] Ginger, J. M., \& Davidhizar, R. E. (2008).Transcultural nursing: Assessment and intervention (5th ed.). USA: Mosby Elsevier.

[22] Gopee, N. (2008). Mentoring and supervision in health care. New Delhi, India: Sage.

[23] Government of the Republic of Namibia (GRN). (1990). Constitution of the Republic of Namibia. Windhoek: Government of the Republic of Namibia.

[24] Government of the Republic of Namibia (GRN).Ministry of Health and Social Services (MOHSS) (1992).The Official National Primary Health Care/Community Based Health Care Guidelines. Windhoek Namibia: Ministry of Health and Social Services.

[25] Government of the Republic of Namibia (GRN) Ministry of Health and Social Services (MOHSS). (January 1995). The Integrated Health Care Delivery: The challenges of implementation. A situation analysis and practical implementation guide.Windhoek $\mathrm{Na}-$ mibia: Ministry of Health and Social Services.

[26] Guest, D., \& Scullion, P. (2007).Study skills for nursing and midwifery students. Berkshire, England: McGraw Hill, Open University Press.

[27] Hess, E. D., \& Cameron, K. S. (2006). Leading with values: Positivity, virtue and high performance.Cambridge, UK: Cambridge University Press. http://dx.doi.org/10.1017/CBO9780511753770.

[28] Hopwood, G., Namibia Institute of Democracy (NID). (2008) Guide to Namibian politics. Windhoek, Namibia: John Meinert.

[29] Ivancevich, J. M., Konopaske, R., \& Matteson, M. T (2008).Organizational behavior and management (9th ed.). New York, USA: McGraw-Hill, Irwin.

[30] Jamerson, P. A., \& Vermeersch, P. (2012). The role of the nurse research facilitator in building research capacity in the clinical setting.Journal of Nursing Administration, 42(1), 21-27. http://dx.doi.org/10.1097/NNA.0b013e31823c180e.

[31] Jones, R. A. P. (2007). Nursing leadership and management: Theories, processes and practices. Philadelphia, PA: FA Davis.

[32] Jooste, K. (2009). Supervision in nursing practice:Professional nurses series. Pretoria, South Africa: Van Schaik.
[33] Jooste, K. (2010). The principles and practice of nursing and health care:Ethos and professional practice, management, staff development and research. Pretoria, South Africa: Van Schaik.

[34] Mank, K. (2006). Gerontological nursing: Competencies for care. Canada: Jones and Bartlett.

[35] Mathis, R. L., \& Jackson, J. H. (2000). Human resource management (9th ed.). Canada: South-Western College Publishing.

[36] Monekosso, G. L. (1994). District health management planning. Implementing and monitoring a minimum health for all package.Geneva: World Health Organization, Regional Office for Africa.

[37] Morrison, J. (2008). The relationship between emotional intelligence and preferred conflict-handling styles. Journal of Nursing Management, 16, 974-983. http://dx.doi.org/10.1111/j.13652834.2008.00876.x.

[38] Muller, M., Bezuidenhout, M., \& Jooste, K. (2006). Health care services management. Cape Town, South Africa: Juta.

[39] Muller, M. (2001). Nursing dynamics (3rd ed.). Cape Town: Heinemann.

[40] Nursing Professions Act 8 of 2004.Government Gazette of the Republic of Namibia. 3249. Namibia. Windhoek: Government printer

[41] Oxford Advanced Learner's Dictionary. (2010). (8th ed.). International Students's edition. Oxford, UK: Oxford University Press.

[42] Pilgrim, D. (2010). The hegemony of cognitive-behaviour therapy in modern mental health care.Health Sociology Review, 20(2), 120132. http://dx.doi.org/10.5172/hesr.2011.20.2.120.

[43] Pretorius, L. (2008). An educational programme to facilitate critical thinking of student nurses in Namibia.Submitted in accordance with the requirements for the degree of Doctor in Nursing Science at the University of Namibia. Windhoek: University of Namibia.

[44] Rassool, G. H. (2009). Alcohol and drug misuse: A handbook for students and health professionals. New York, USA: Routledge, Taylor \& Francis.

[45] Rossouw, D., Le Roux, S. J., \& Groenewald, D. (2003). Strategic management:An applied South African perspective. Cape Town, South Africa: New Africa Education.

[46] Searle, C. (1987). Professional practice:A South African nursing perspective. Durban: Butterworths.

[47] Searle, C., Human, S., \& Mogotlane, S. M. (2009). Professional practice: A southern African nursing perspective (5th ed.). Johannesburg, South Africa: Heinemann.

[48] Smit, P. J., Cronje, G. J., Brevis, T., \& Urba, M. J. (2007). Management principles: A contemporary edition for Africa (4th ed.). Cape Town, South Africa: Juta.

[49] Stanhope, M., \& Lancaster, J. (2008). Public health nursing: Population-centered health care in the community (7th ed.). Canada: Mosby, Elsevier.

[50] Stanhope, M., \& Lancaster, J. (2000).Community \& public health nursing (5th ed.). New York: Mosby.

[51] Stanhope, M., \& Lancaster, J. (2006). Foundations of nursing in the community: Community-oriented practice (2nd ed.). China: MosbyElsevier.

[52] Stanhope, M., \& Lancaster, J. (2010). Foundations of Nursing in the

[53] Community-Community oriented Practice. ( ${ }^{\text {rd }}$ ed.). St. Louis, MO Mosby.

[54] Tomey, A. M. (2009).Guide to nursing management and leadership (8th ed.). Canada: Mosby Elsevier.

[55] Vlok, M. E. (1996). Manual of community nursing and communicable diseases (5th ed.). Cape Town: Juta.

[56] World Health Organization (WHO). (2009). WHO: Primary health care. Accessed from http://www.who.int/topics/primary health care/en/.on the 6/6/2009. 